\title{
Systematic Review and Meta-Analysis of the Blood Glutathione Redox State in Chronic Obstructive Pulmonary Disease
}

\author{
Salvatore Sotgia ${ }^{1, * \mathbb{C}}$, Panagiotis Paliogiannis ${ }^{2}{ }^{\mathbb{D}}$, Elisabetta Sotgiu ${ }^{1}$, Sabrina Mellino ${ }^{1}$, \\ Elisabetta Zinellu ${ }^{3}$, Alessandro G. Fois ${ }^{2,3}$, Pietro Pirina 2,3 (D), Ciriaco Carru 1,4 (D), \\ Arduino A. Mangoni ${ }^{5}$ (D) and Angelo Zinellu ${ }^{1}$ (D) \\ 1 Department of Biomedical Sciences, School of Medicine, University of Sassari, 07100 Sassari, Italy; \\ eli.sotgiu@alice.it (E.S.); sabrinamellino3@gmail.com (S.M.); carru@uniss.it (C.C.); azinellu@uniss.it (A.Z.) \\ 2 Department of Clinical and Experimental Medicine, School of Medicine, University of Sassari, \\ 07100 Sassari, Italy; panospaliogiannis@gmail.com (P.P.); agfois@uniss.it (A.G.F.); pirina@uniss.it (P.P.) \\ 3 Department of Respiratory Diseases, University Hospital Sassari (AOU-SS), 07100 Sassari, Italy; \\ elisabetta.zinellu@aousassari.it \\ 4 Quality Control Unit, University Hospital Sassari (AOU-SS), 07100 Sassari, Italy \\ 5 Discipline of Clinical Pharmacology, College of Medicine and Public Health, Flinders University and \\ Flinders Medical Centre, Adelaide 5001, Australia; arduino.mangoni@flinders.edu.au \\ * Correspondence: ssotgia@uniss.it; Tel.: +39-079-229-775; Fax: +39-079-228-120
}

Received: 28 October 2020; Accepted: 17 November 2020; Published: 18 November 2020

\begin{abstract}
The aim of this systematic review and meta-analysis was to assess the blood concentrations of the total and reduced forms of the low-molecular-weight antioxidant thiol glutathione (GSH) in chronic obstructive pulmonary disease (COPD) patients in comparison to healthy individuals. A literature search was conducted in the PubMed and Web of Science databases from inception until June 2020. In the 18 studies identified (involving a total of 974 COPD patients and 631 healthy controls), the pooled reduced GSH concentrations were significantly lower in patients with COPD than controls (SMD $=-3.04,95 \% \mathrm{CI}=-4.42$ to $-1.67 ; p<0.001$ ). By contrast, the pooled total GSH concentrations were significantly higher in patients with COPD than controls (SMD $=0.42$, $95 \% \mathrm{CI}=0.11$ to $0.73 ; p=0.009$ ). Our meta-analysis showed that the blood concentrations of reduced GSH, even in the presence of higher total GSH concentrations, were significantly lower in patients with COPD when compared to healthy controls. This suggests that an impaired antioxidant defense system plays an important role in the pathogenesis of COPD.
\end{abstract}

Keywords: chronic obstructive pulmonary disease (COPD); glutathione; oxidative stress

\section{Introduction}

Chronic obstructive pulmonary disease (COPD), a non-communicable respiratory disease with an estimated prevalence of $4-20 \%$ in adults over 40 years worldwide, is characterized by progressive airflow limitation and emphysematous changes in the lungs [1,2]. According to the Global Burden of Disease Study, COPD is the third leading cause of death worldwide and is expected to become the leading cause by the year 2030 [3]. COPD is typically characterized by a chronic local and systemic inflammatory response that is largely driven by oxidative stress $[4,5]$. The increased oxidative burden in the lungs is due to exposure to environmental oxidants, such as air pollution, occupational dust or cigarette smoking [6,7], as well as the endogenous generation of oxidants by several types of cells and the mitochondrial electron transport chain [4]. Oxidative stress, resulting from an excess of oxidants and/or a deficit in antioxidant defense mechanisms, favors lung tissue damage and activates specific molecular 
mechanisms that initiate local inflammation [8]. The latter involves the activation of epithelial cells and resident macrophages, and the recruitment and activation of neutrophils, eosinophils, monocytes and lymphocytes that release a variety of pro-inflammatory mediators, including cytokines, chemokines, growth factors and lipid mediators [4]. Both inflammatory and structural cells also produce reactive oxygen species (ROS) [9,10], with a consequent shift in the intracellular thiol/disulfide redox state toward more oxidative conditions [11]. The perturbation of thiol concentrations in COPD is therefore regarded as the hallmark of oxidative stress, which involves either excessive ROS production and/or impaired antioxidant defense mechanisms [12]. Among the low-molecular-weight thiols, glutathione (GSH, L- $\gamma$-glutamyl-L-cysteinyl-glycine) accounts for $90 \%$ of intracellular non-protein thiols [13]. The assessment of the concentrations of GSH, one of the primary non-enzymatic antioxidants in the lung, has received significant attention in COPD [14], as it plays a key role in the maintenance of cellular redox potentials and homeostatic mechanisms [15]. GSH concentrations have been investigated in different biological matrices such as sputum [16], exhaled breath condensate [17], bronchoalveolar lavage [18], blood [19] and lung tissue [20]. The concentrations of GSH in biological fluids that are functionally and anatomically close to the lung are several times higher than those in the plasma, e.g., 200-400 $\mu \mathrm{M}$ in the epithelial lining fluid vs. $2-4 \mu \mathrm{M}$ in the plasma [21]. However, the collection of lung lining specimens is invasive and not well standardized [22], as there is no consensus on how to normalize the dilution process introduced during the sampling. Therefore, albeit with the inherent limitation of not capturing the local antioxidant/oxidant balance, studies in COPD have generally focused on circulating GSH concentrations, with conflicting results. We sought to address these discrepancies by conducting a systematic review and meta-analysis on the available evidence regarding the association between blood GSH concentrations and COPD.

\section{Materials and Methods}

\subsection{Search Strategy, Eligibility Criteria and Study Selection}

An electronic search was performed in the PubMed and Web of Science databases, from inception until June 2020, using a combination of the following terms: glutathione, GSH, chronic obstructive pulmonary disease, and COPD. The references of the retrieved articles were also searched to identify additional studies. The full-text paper selection criteria included (i) primary research studies, (ii) assessments of GSH in red blood cells or whole blood, (iii) case-control designs, (iv) sample sizes $\geq 10$ patients with COPD and (v) full-text papers in English. The articles were independently reviewed by two investigators. A third investigator was involved in the case of disagreement between peers. The quality of each study was assessed using the Newcastle-Ottawa scale [23], which takes into account the cohort selection, the comparability of the cohorts based on the design or analysis, how the exposure was determined and how the outcomes of interest were evaluated. A score of six or more was taken as the quality threshold.

\subsection{Statistical Analysis}

Because of the different units of measurement $(\mathrm{g} / \mathrm{L}, \mathrm{mol} / \mathrm{L}$ or $\mathrm{mol} / \mathrm{g} \mathrm{Hb})$ used to express the blood GSH concentrations in primary studies, forest plots of continuous data and the assessment of the differences in blood GSH concentrations in COPD patients vs. healthy controls were expressed using the standardized mean differences (SMDs). When primary studies reported concentrations as median and interquartile range (IQR), the values of the mean and standard deviation were estimated as described by Wan et al. (2014) [24]. When the standard error (SE) was used instead of the standard deviation, the latter was estimated by multiplying the SE by the square root of the sample size. The heterogeneity between studies was assessed with Cochran's Q statistic, with a significance level of $p<0.10$. The magnitude of the heterogeneity was assessed with the $\mathrm{I}^{2}$ statistic, and the $\mathrm{I}^{2}$ values were interpreted as follows: $\mathrm{I}^{2}<25 \%$, no heterogeneity; $\mathrm{I}^{2}$ between $25 \%$ and $50 \%$, moderate heterogeneity; $\mathrm{I}^{2}$ between $50 \%$ and $75 \%$, large heterogeneity; and $\mathrm{I}^{2}>75 \%$, extreme heterogeneity $[25,26]$. A random-effects model was used to 
perform the meta-analysis in the case of substantial heterogeneity. Sensitivity analysis was performed to assess the robustness of the meta-analysis, excluding a single case-control study each time and recalculating the effect size [27]. The presence of publication bias and the associations between the size of the study and the size of the effect were assessed, respectively, by Egger's regression asymmetry test at a $p<0.05$ level of significance and the Begg's adjusted rank correlation [28,29]. The Duval and Tweedie "trim and fill" procedure was carried out to further test the occurrence of publication bias [30]. Confidence intervals at 95\% (CIs) were reported for each effect size and the overall effect, and $p<0.05$ was considered statistically significant. The study was fully compliant with the principles outlined in the PRISMA Statement [31]. Statistical analyses were performed using Small Stata for Windows, version 14.1, 64 bit (StataCorp LP, College Station, TX, USA).

\section{Results}

\subsection{Literature Search and Study Selection}

A flow chart describing the screening process is presented in Figure 1.

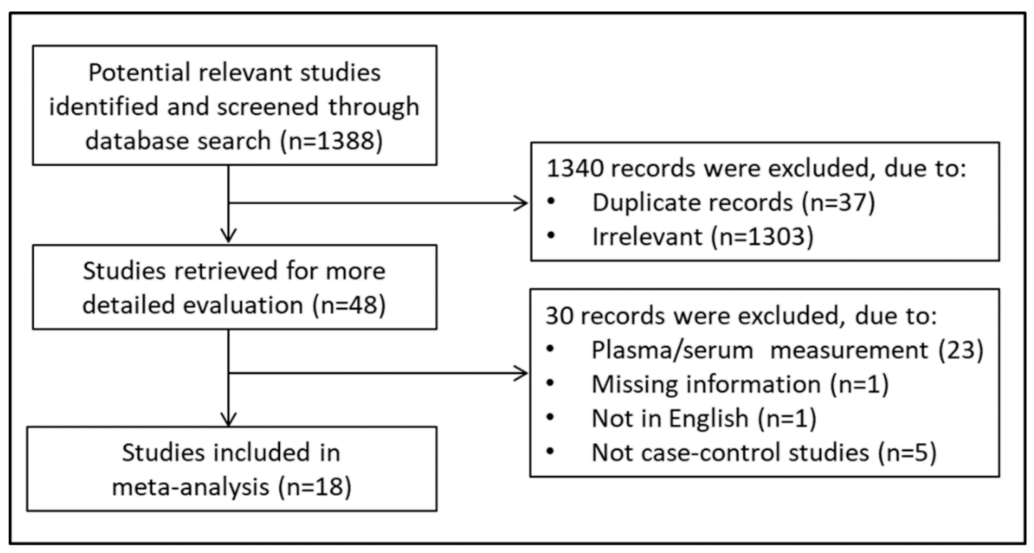

Figure 1. Flow chart of study selection.

The initial search yielded 1388 articles. Of them, 1340 were excluded because they were either irrelevant or duplicates. After a full-text review of the remaining 48 articles, a further 30 were excluded, as they did not meet the inclusion criteria, leaving the remaining 18 for further analysis [32-49]. The retrieved studies were published between 2002 and 2019, and their characteristics are described in Table 1. 
Table 1. Summary of the studies on chronic obstructive pulmonary disease (COPD) vs. controls included in the meta-analysis. ${ }^{*}$ Mean and standard deviation (SD) were estimated from formulas using the median and range as described by Wan et al. [4]. NOS: Newcastle-Ottawa quality assessment scale for case-control studies. NR: not reported; Red: reduced; Tot: total. RBC: red blood cell; WB: whole blood.

\begin{tabular}{|c|c|c|c|c|c|c|c|c|c|c|c|c|c|}
\hline \multirow[b]{2}{*}{$\begin{array}{l}\text { First Author, } \\
\text { Year, Country }\end{array}$} & \multirow[b]{2}{*}{ Diagnosis } & \multirow[b]{2}{*}{$\begin{array}{l}\text { NOS } \\
\text { (Stars) }\end{array}$} & \multirow[b]{2}{*}{ Matrix } & \multirow[b]{2}{*}{$\begin{array}{l}\text { GSH } \\
\text { Form }\end{array}$} & \multirow[b]{2}{*}{$\begin{array}{l}\text { Measurement } \\
\text { Units }\end{array}$} & \multicolumn{4}{|c|}{ Control Group } & \multicolumn{4}{|c|}{ COPD Group } \\
\hline & & & & & & $n$ & $\begin{array}{c}\text { Age } \\
\text { (Years) }\end{array}$ & $\begin{array}{c}\text { Gender } \\
(\mathrm{M} / \mathrm{F})\end{array}$ & $\begin{array}{c}\text { GSH } \\
\text { Mean } \pm \text { SD }\end{array}$ & $n$ & $\begin{array}{c}\text { Age } \\
\text { (Years) }\end{array}$ & $\begin{array}{l}\text { Gender } \\
(\mathrm{M} / \mathrm{F})\end{array}$ & $\begin{array}{c}\text { GSH } \\
\text { Mean } \pm \text { SD }\end{array}$ \\
\hline Calikoglu et al. 2002, Turkey & BTS & 8 & RBC & Red & $\mu \mathrm{mol} / \mathrm{gHb}$ & 30 & 62.56 & $15 / 15$ & $4.75 \pm 0.64$ & 41 & 58.21 & $20 / 21$ & $3.49 \pm 1.06$ \\
\hline Agacdiken et al. 2004, Turkey & NR & 8 & WB & Red & $\mathrm{mg} / \mathrm{dL}$ & 10 & 49 & $10 / 0$ & $22.4 \pm 16.6$ & 21 & 63 & $21 / 0$ & $8.37 \pm 7$ \\
\hline Faucher et al. 2004, France & NR & 6 & RBC & Red & $\mathrm{nmol} / \mathrm{mL}$ & 8 & 59 & $7 / 1$ & $1511 \pm 461$ & 30 & 66 & $29 / 1$ & $1006 \pm 537$ \\
\hline Foschino Barbaro et al. 2005, Italy & GOLD & 6 & RBC & Red & $\mu \mathrm{mol} / \mathrm{L}$ & 15 & 61 & $15 / 0$ & $741 \pm 101$ & 45 & 62 & $45 / 0$ & $769 \pm 89$ \\
\hline Flaring et al. 2005, Sweden & NR & 6 & WB & Tot & $\mu \mathrm{mol} / \mathrm{L}$ & 10 & 42 & $3 / 7$ & $1206 \pm 264 *$ & 21 & 75 & NR & $1231 \pm 184$ * \\
\hline Nadeem et al. 2005, India & GOLD & 8 & WB & Tot & $\mathrm{mmol} / \mathrm{L}$ & 20 & NR & $20 / 0$ & $0.420 \pm 0.057$ & 76 & NR & $76 / 0$ & $0.754 \pm 0.043$ \\
\hline Parija et al. 2005, India & NR & 8 & WB & Red & $\mathrm{mg} / \mathrm{gHb}$ & 11 & 55 & $9 / 2$ & $1.79 \pm 0.24$ & 11 & 57 & $10 / 1$ & $1.37 \pm 0.24$ \\
\hline Rai et al. 2006, India & NR & 6 & WB & Red & $\mathrm{mg} / \mathrm{dL}$ & 50 & $22-55$ & NR & $30.6 \pm 5.75$ & 24 & $35-65$ & NR & $30.2 \pm 5.39$ \\
\hline Jammes et al. 2008, Senegal & ATS/ERS & 6 & $\mathrm{RBC}$ & Red & $\mathrm{nmol} / \mathrm{mL}$ & 18 & 48 & $13 / 5$ & $1953 \pm 1107$ & 17 & 53 & $13 / 4$ & $1565 \pm 495$ \\
\hline Mercken et al. 2009, Netherlands & GOLD & 9 & $R B C$ & Red & $\mu \mathrm{mol} / \mathrm{gHb}$ & 10 & 56 & $4 / 6$ & $4.30 \pm 1.24$ & 15 & 57 & $10 / 5$ & $3.82 \pm 1.75$ \\
\hline Biljak et al. 2010, Croatia & GOLD & 6 & RBC & Tot & $\mu \mathrm{mol} / \mathrm{L}$ & 51 & 52 & $21 / 30$ & $221 \pm 114^{*}$ & 109 & 71 & $82 / 27$ & $259 \pm 77^{*}$ \\
\hline Ahmad et al. 2013, India & GOLD & 6 & WB & Tot & $\mathrm{mmol} / \mathrm{L}$ & 75 & 42 & $53 / 22$ & $0.84 \pm 0.34$ & 140 & 45 & $111 / 29$ & $0.93 \pm 0.47$ \\
\hline Arja et al. 2013, India & GOLD & 6 & RBC & Red & $\mathrm{nmol} / \mathrm{mL}$ & 150 & 61 & $150 / 0$ & $4.02 \pm 0.17$ & 236 & 63 & $236 / 0$ & $2.88 \pm 0.20$ \\
\hline Elmasry et al. 2015, Egypt & GOLD & 6 & WB & Red & $\mathrm{mg} / \mathrm{dL}$ & 40 & 54 & $31 / 9$ & $23.3 \pm 0.6$ & 34 & 55 & $27 / 7$ & $8.9 \pm 1.1$ \\
\hline Kodama et al. 2017, Japan & GOLD & 6 & WB & Red & $\mu \mathrm{mol} / \mathrm{L}$ & 28 & 69 & $19 / 9$ & $892 \pm 122$ & 39 & 73 & $34 / 5$ & $742 \pm 262$ \\
\hline Al-Azzawi et al. 2017, India & ATS/ERS & 6 & WB & Red & $\mu \mathrm{g} / \mathrm{mL}$ & 40 & 45 & $28 / 12$ & $41.53 \pm 1.54$ & 30 & 65 & $21 / 9$ & $13.8 \pm 1.3$ \\
\hline Jha et al. 2019, India & GOLD & 6 & RBC & Red & $\mu \mathrm{mol} / \mathrm{gHb}$ & 40 & 55 & $31 / 9$ & $8.3 \pm 1.1$ & 60 & 59 & $36 / 24$ & $9.2 \pm 1.3$ \\
\hline Saribal et al. 2019, Turkey & NR & 7 & RBC & Red & $\mathrm{mg} / \mathrm{dL}$ & 25 & NR & $25 / 0$ & $25.7 \pm 2.1$ & 25 & NR & $25 / 0$ & $16.1 \pm 5.1$ \\
\hline
\end{tabular}


A total of 1605 subjects, 974 COPD patients (82\% males) and 631 controls (72\% males), were evaluated. The mean age ranged between 42.0 and 75.7 years in the COPD patients and between 43.7 and 77.7 years in the controls. The blood concentrations of reduced GSH (rGSH) were measured in 14 studies [34-37,39-42,44-49], while total GSH (tGSH) was measured in four studies $[32,33,38,43]$. GSH was measured in red blood cells (RBCs) in nine studies and in whole blood (WB) in the other nine. The GSH concentrations were reported as the median and IQR, mean and SE, and mean and standard deviation. COPD was diagnosed according to the GOLD guidelines in nine articles [33,37,38,42-46,48], the ATS/ERS guidelines in two studies [41,47] and the BTS guidelines in one study [34]. Six studies did not report the guidelines used for COPD diagnosis [32,35,36,39,40,49].

\subsection{Blood Reduced GSH (rGSH) and COPD}

When compared to healthy controls, the blood (RBCs/WB) rGSH concentrations in COPD patients were significantly lower in 10 studies [34-36,39,41,44-47,49], significantly higher in one study [48], and non-significantly different in the remaining three studies [37,40,42]. A forest plot of the blood rGSH concentrations in COPD patients vs. healthy subjects is presented in Figure 2.

\begin{tabular}{|c|c|c|c|c|c|}
\hline \multicolumn{3}{|l|}{ Study } & \multirow{2}{*}{$\begin{array}{l}\text { COPD } \\
\mathrm{N}, \text { mean (SD) }\end{array}$} & \multirow{2}{*}{$\begin{array}{l}\text { CTRL } \\
\mathrm{N} \text {, mean (SD) }\end{array}$} & \multirow{2}{*}{$\begin{array}{l}\% \\
\text { Weight }\end{array}$} \\
\hline Name & Year & SMD (95\% Cl) & & & \\
\hline Calikoglu et al. & 2002 & $-1.39(-1.91,-0.86)$ & $41,3.49(1.06)$ & $30,4.75(.64)$ & 7.46 \\
\hline Agacdiken et al. & 2004 & $-1.28(-2.11,-0.46)$ & $21,8.37(7)$ & $10,22.4(16.6)$ & 7.35 \\
\hline Faucher et al. & 2004 & $-0.97(-1.78,-0.15)$ & $30,1006(537)$ & $8,1511(461)$ & 7.35 \\
\hline Foschino Barbaro et al. & 2005 & $0.30(-0.28,0.89)$ & $45,769(89)$ & $15,741(101)$ & 7.44 \\
\hline Parija et al. & 2005 & $-1.75(-2.75,-0.75)$ & $11,1.37(.24)$ & $11,1.79(.24)$ & 7.26 \\
\hline Rai et al. & 2006 & $-0.07(-0.56,0.42)$ & $24,30.2(5.39)$ & $50,30.6(5.75)$ & 7.47 \\
\hline Jammes et al. & 2008 & $-0.45(-1.12,0.22)$ & 17,1565 (495) & $18,1953(1107)$ & 7.41 \\
\hline Mercken et al. & 2009 & $-0.31(-1.11,0.50)$ & $15,3.82(1.75)$ & $10,4.3(1.24)$ & 7.35 \\
\hline Arja et al. & 2013 & $-6.03(-6.51,-5.56)$ & $236,2.88(.2)$ & $150,4.02(.17)$ & 7.48 \\
\hline Elmasry et al. & $2015 \multimap$ & $-16.63(-19.39,-13.88)$ & $34,8.9(1.1)$ & $40,23.3(.6)$ & 5.79 \\
\hline Kodama et al. & 2017 & $-0.70(-1.20,-0.20)$ & $39,742(262)$ & $28,892(122)$ & 7.47 \\
\hline Al-Azzawi et al. & $2017 \multimap$ & $-19.22(-22.49,-15.96)$ & $30,13.8(1.3)$ & $40,41.5(1.54)$ & 5.29 \\
\hline Jha et al. & 2019 & $0.74(0.32,1.15)$ & $60,9.2(1.3)$ & $40,8.3(1.1)$ & 7.49 \\
\hline Saribal et al. & 2019 & $-2.46(-3.20,-1.72)$ & $25,16.1(5.1)$ & $25,25.7(2.1)$ & 7.38 \\
\hline \multicolumn{2}{|c|}{ Overall $(\mathrm{I}$-squared $=98.4 \%, \mathrm{p}=0.000)$} & $-3.04(-4.42,-1.67)$ & 628 & 475 & 100.00 \\
\hline
\end{tabular}

Figure 2. Forest plot of studies examining blood reduced GSH and COPD.

Because of the high heterogeneity $\left(\mathrm{I}^{2}=98.4 \%, p<0.001\right)$, a random-effects model was used to calculate the pooled standardized mean difference (SMD). The latter showed that the rGSH concentrations were significantly lower in COPD patients than controls $(\mathrm{SMD}=-3.04,95 \% \mathrm{CI}=-4.42$ to $-1.67 ; p<0.001$ ). Despite the potentially distortive effects of two studies [45,47], a sensitivity analysis performed by recalculating the confidence interval of the pooled effect size after eliminating each study at a time showed no substantial modification of the effect size, which ranged between -2.10 and -3.37 (Figure 3). 


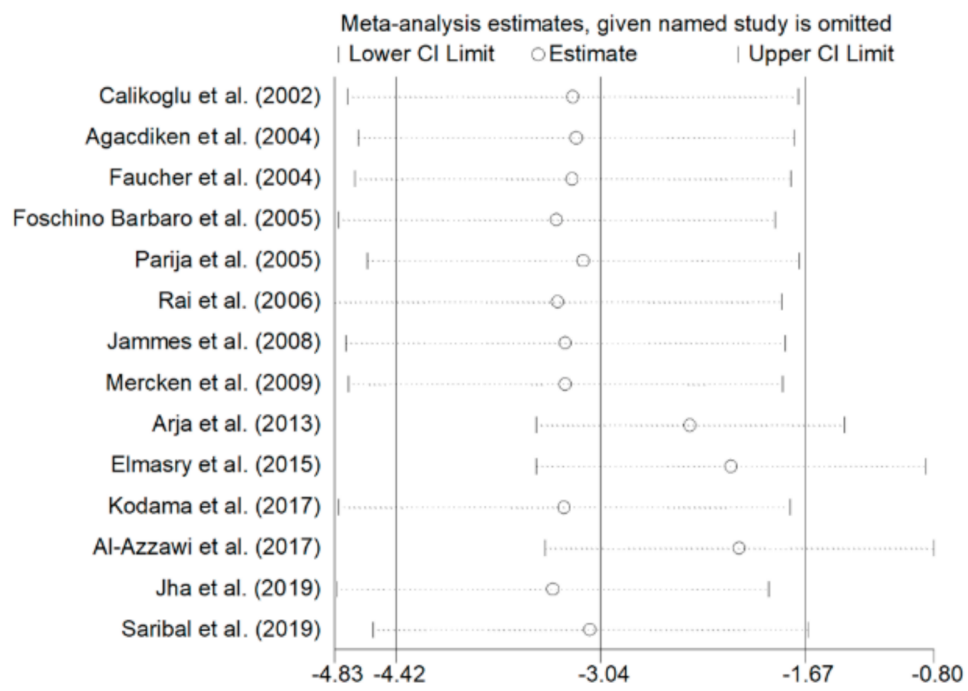

Figure 3. Sensitivity analysis of the association between blood reduced GSH and COPD. The influence of individual studies on the overall standardized mean difference (SMD) is shown. The middle vertical axis indicates the overall SMD, and the two vertical axes indicate the $95 \%$ confidence intervals (CI). Hollow circles represent the pooled SMD when the remaining study was omitted from the meta-analysis. Two ends of each broken line represent 95\% CIs.

The funnel plot in Figure 4 confirms the distortive effects of the two above-mentioned studies. Their removal attenuated the effect size (SMD $=-1.20,95 \% \mathrm{CI}=-2.42$ to $0.030, p=0.056$ ) without influencing the magnitude of the heterogeneity $\left(\mathrm{I}^{2}=98.0 \%, p<0.001\right)$.

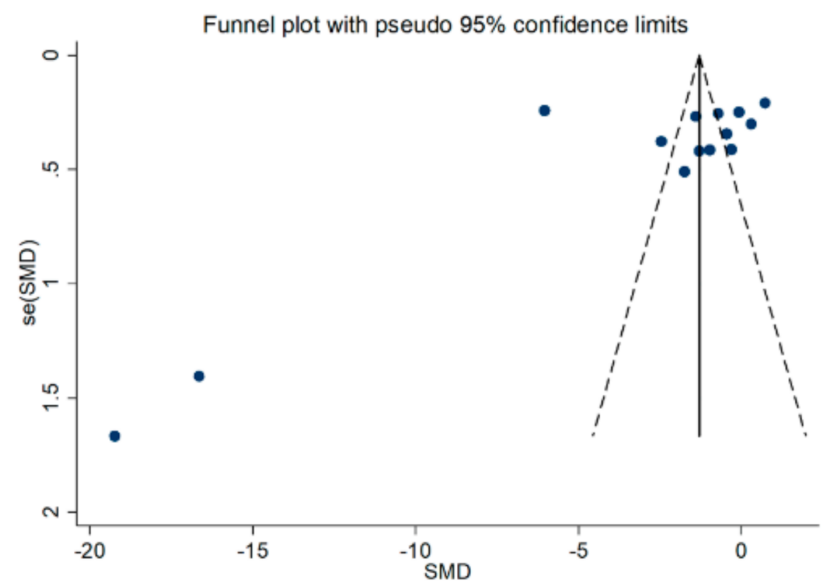

Figure 4. Funnel plot of studies investigating healthy controls and patients with COPD.

The analysis of the 12 remaining studies showed a lack of publication bias (Begg's test, $p=0.19$; Egger's test, $p=0.95$ ). The trim-and-fill method found five potential missing studies to add on the left side of the funnel plot to ensure the symmetry (Figure 5), with a resulting adjusted SMD of $-2.32 ; 95 \%$ $\mathrm{CI}=-3.57$ to $-1.07, p<0.001$. 


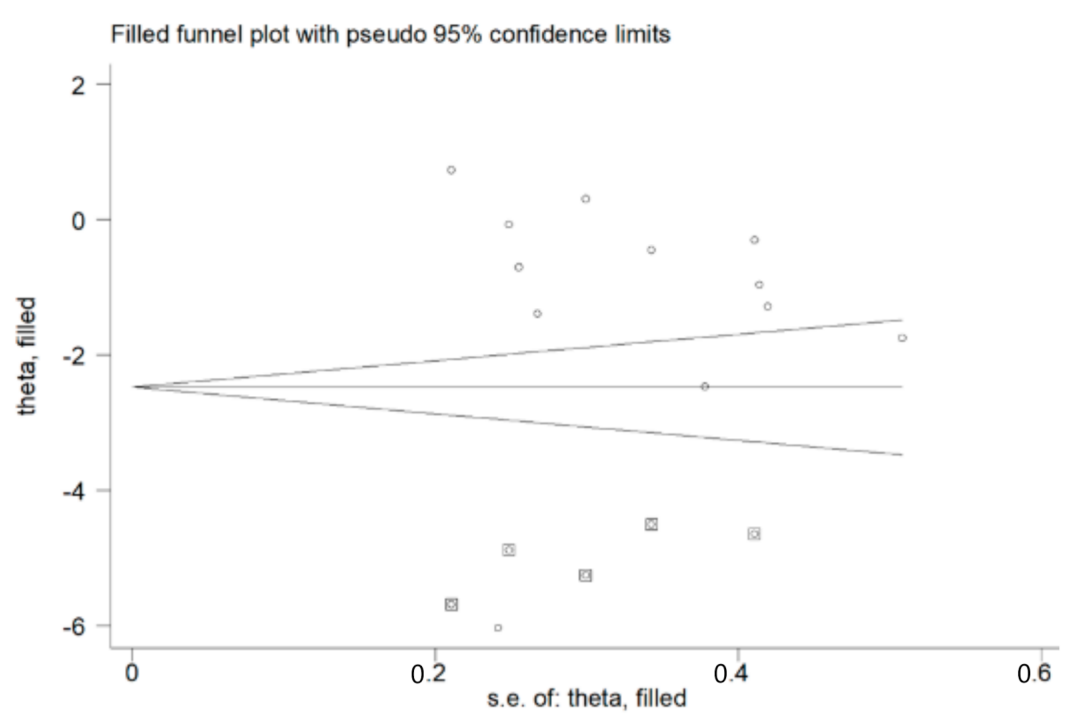

Figure 5. Funnel plot of studies investigating healthy controls and patients with COPD after trimming and filling. Dummy studies and genuine studies are represented by enclosed circles and free circles, respectively.

The age, gender, body mass index (BMI), forced expiratory volume at $1 \mathrm{~s}$ (FEV1), FEV1/forced vital capacity (FVC), malondialdehyde (MDA), biological matrix (RBCs/WB), continent where the study was conducted (Europe, Africa or Asia), publication year and guidelines used for COPD diagnosis were investigated as potential contributors to the between-study variance in meta-regression analysis. The MDA levels were significantly associated with the SMD $(t=-3.40, p=0.009$, Figure 6).

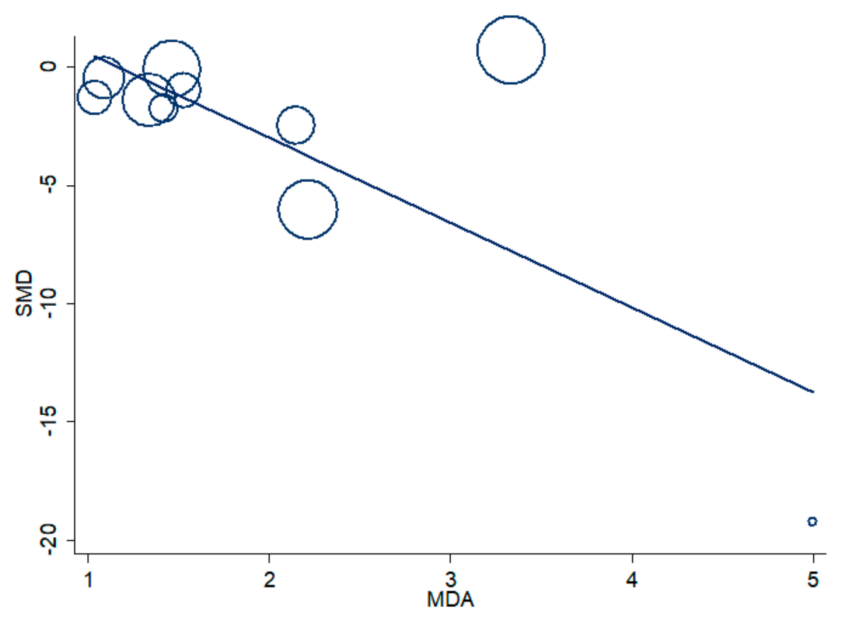

Figure 6. Meta-regression analysis of malondialdehyde serum concentration and SMD.

By contrast, no significant associations were observed with age $(\mathrm{t}=-1.71, p=0.12)$, gender $(\mathrm{t}=0.52$, $p=0.61)$, BMI $(\mathrm{t}=-1.13, p=0.34)$, FEV1 $(\mathrm{t}=0.64, p=0.55)$, FEV1/FVC $(\mathrm{t}=-0.70, p=0.51)$, biological matrix $(\mathrm{t}=-1.60, p=0.14)$, continent $(\mathrm{t}=-1.45, p=0.18)$, publication year $(\mathrm{t}=-1.54$, $p=0.15)$ or type of guidelines $(t=-1.45, p=0.17)$. Methodological factors, such as the use of an in-house spectrophotometric assay vs. commercial spectrophotometric kit, were also explored as potential contributors to the heterogeneity (Figure 7). The SMD values in studies using in-house assays (SMD $=-4.31,95 \%=-6.26$ to $\left.-2.37, p<0.001 ; \mathrm{I}^{2}=98.8 \%, p<0.001\right)$ were not significantly different from those in studies using commercial ones ( $\mathrm{SMD}=-0.68,95 \% \mathrm{CI}=-1.04$ to $-0.32, p<0.001$; $\left.\mathrm{I}^{2}=0.0 \%, p<0.63 ; \mathrm{t}=0.89, p=0.39\right)$. 


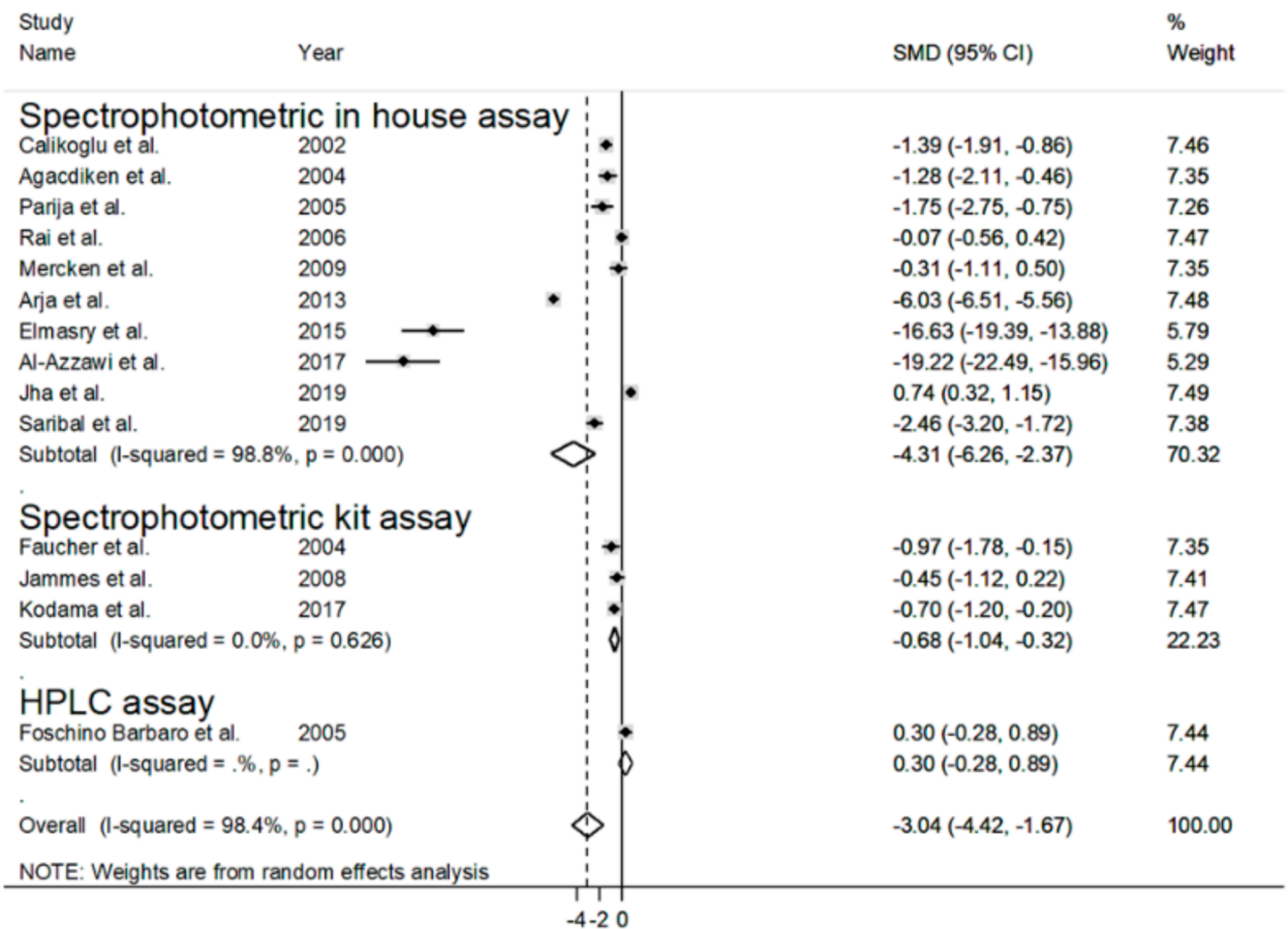

Figure 7. Forest plot of studies examining blood reduced GSH and COPD according to assay method used to detect GSH.

\subsection{Blood Total GSH (tGSH) and COPD}

Blood tGSH concentrations were significantly higher in COPD patients vs. controls in three studies $[33,38,43]$, while no significant between-group differences were observed in one study [32]. A forest plot of blood tGSH concentrations in COPD patients vs. healthy subjects is presented in Figure 8.

\begin{tabular}{|c|c|c|c|c|c|}
\hline \multicolumn{2}{|l|}{ Study } & \multicolumn{2}{|r|}{ COPD } & CTRL & $\%$ \\
\hline Name & Year & $\operatorname{SMD}(95 \% \mathrm{Cl})$ & $\mathrm{N}$, mean (SD) & $\mathrm{N}$, mean (SD) & Weight \\
\hline Flaring et al. & 2005 & $0.12(-0.64,0.87)$ & $21,1231(184)$ & $10,1206(264)$ & 12.78 \\
\hline Nadeem et al. & 2005 & $0.94(0.43,1.45)$ & $76,754(375)$ & $20,420(255)$ & 21.23 \\
\hline Biljak et al. & 2010 & $0.42(0.08,0.76)$ & $109,259(77)$ & $51,221(114)$ & 31.15 \\
\hline Ahmad et al. & 2013 & $0.21(-0.07,0.49)$ & $140, .93(.47)$ & $75, .84(.34)$ & 34.85 \\
\hline \multicolumn{2}{|c|}{ Overall (I-squared $=54.6 \%, p=0.086$ ) } & $0.42(0.11,0.73)$ & 346 & 156 & 100.00 \\
\hline \multicolumn{2}{|c|}{ NOTE: Weights are from random effects analysis } & & & & \\
\hline
\end{tabular}

Figure 8. Forest plot of studies examining blood total GSH and COPD. 
A large heterogeneity among the studies was observed $\left(\mathrm{I}^{2}=54.6 \%, p=0.086\right)$; therefore, a random-effects model was used to compute the overall effect. The pooled SMD showed that tGSH concentrations were significantly higher in COPD patients than controls (SMD $=0.42,95 \% \mathrm{CI}=0.11$ to $0.73 ; p=0.009$ ). As shown in Figure 9 , the effect size did not substantially change following the removal of each single case-control study at a time (the effect size ranged between 0.28 and 0.53 ). An analysis of the publication bias and meta-regression analysis were not performed because of the limited number of studies.

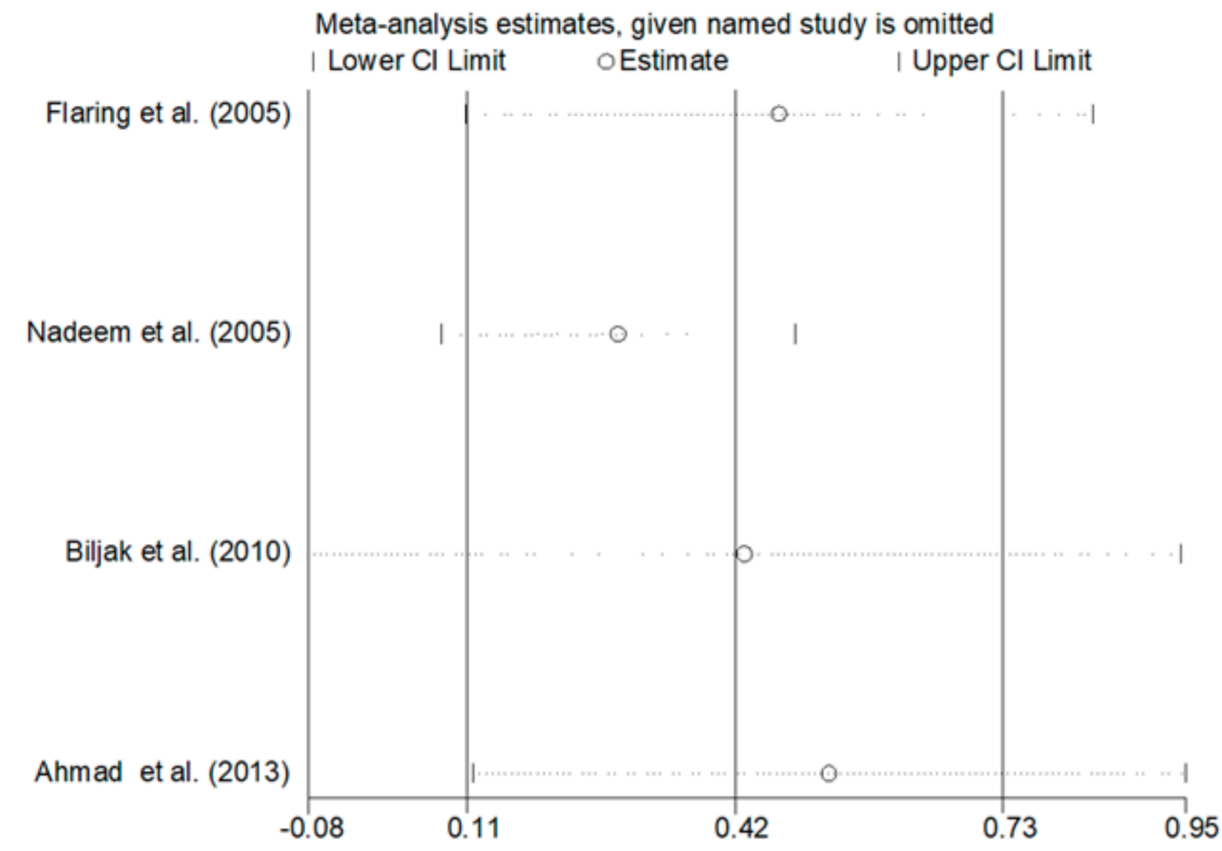

Figure 9. Sensitivity analysis of the association between blood total GSH and COPD. The influence of individual studies on the overall standardized mean difference (SMD) is shown. The middle vertical axis indicates the overall SMD, and the two vertical axes indicate the $95 \%$ confidence intervals (CI). Hollow circles represent the pooled SMD when the remaining study was omitted from the meta-analysis. Two ends of each broken line represent 95\% CIs.

\section{Discussion}

Although the presence of systemic oxidative stress in COPD patients is generally recognized, less clear is the evidence regarding possible alterations in the blood concentrations of GSH, a key non-enzymatic antioxidant, in this group. Methodological factors related to blood GSH measurement, such as the blood matrix used (WB, RBCs or plasma/serum), the form of GSH measured (reduced or total), the baseline concentrations in different blood matrices, the differences in the handling and pre-treatment of samples and the analytical steps, could account for the contrasting results of published studies. We sought to address these issues by selecting observational studies that specifically measured GSH in RBCs/WB, carefully distinguishing those that measured the reduced form from those that assessed the total form. We excluded primary studies assessing GSH in the plasma/serum, as the much lower basal concentrations of GSH in such matrices, $2-4 \mu \mathrm{mol} / \mathrm{L}$ in the plasma vs. $0.6-3.6 \mathrm{mmol} / \mathrm{L}$ in RBCs, were more likely to be affected by potential differences in the sample handling and/or analytical procedures between the studies $[21,50]$. Similarly, only primary case-control studies were selected, on the basis that any pre-analytical and analytical error would similarly affect both cases and controls. Finally, the SMD was used to make uniform the different scales of measurement used to express GSH concentrations and to minimize the potential effects of improper pre-analytical and/or analytical treatment. Eighteen primary studies, 14 reporting rGSH and four tGSH, fulfilled the inclusion criteria and were further analyzed. Pooled analysis showed that COPD patients have significantly lower 
rGSH, and higher tGSH, concentrations when compared to healthy controls. The lack of a significant reduction in tGSH concentrations in COPD patients suggests the increased oxidation, rather than impaired synthesis, of this thiol. Thus, taken together, these data suggest a downregulation of blood GSH concentrations in COPD resulting from a systemic state of oxidative stress. Meta-regression analysis showed that the observed alterations in GSH concentrations were not associated with age, gender, BMI, FEV1, FEV1/FVC, continent where the study was conducted, publication year, type of guidelines or biological matrix. Similarly, the pooled SMD (size and direction) was not significantly affected by whether an in-house spectrophotometric assay or commercial spectrophotometric kits were used $(\mathrm{t}=0.89, p=0.39)$. However, the extreme heterogeneity observed in studies using home-made methods $\left(\mathrm{I}^{2}=98.8 \%, p<0.001\right)$, which do not have to comply with the standardization requirements for commercial kits, highlights, once again, the importance of methodological factors as a source of variability. Thus, the extreme $\left(\mathrm{I}^{2}=98.4 \%, p<0.001\right)$ and large $\left(\mathrm{I}^{2}=54.6 \%, p=0.086\right)$ heterogeneity observed among the studies estimating, respectively, rGSH and tGSH might also be explained, at least partly, by analytical factors. In most of the retrieved articles, in fact, the sample processing involved the lysis of RBCs and removal of proteins by an acidic step using different reagents such as perchloric acid, trichloroacetic acid, metaphosphoric acid or sulfosalicylic acid. However, it is well-documented that the release of hemoglobin following acidic treatment induces the oxidation of a fraction of GSH, with the associated formation of glutathione disulfide, the occurrence of which is often an artifact [51-53]. Moreover, the detection of GSH is frequently performed using Ellman's reagent, which is not a specific reagent for GSH, as it can react with any free sulfhydryls in solution [54]. Even blood withdrawal may lead to inconsistencies, as the partial oxidation of GSH resulting from an incorrect sample collection technique (e.g., butterfly needle/vacutainer vs. syringe) might occur [55]. Therefore, these methodological issues may affect the variability in GSH concentrations in individual studies. On the other hand, the heterogeneity could also be linked to specific subject characteristics, e.g., smoking and COPD stage. The association observed between the pooled GSH SMD and MDA concentrations in the meta-regression analysis $(\mathrm{t}=-3.40, p=0.009$, Figure 6$)$ supports this proposition, as an increase in plasma MDA concentrations is common in patients with advanced COPD [56,57]. As shown in Figures 3 and 4, the heterogeneity could also be explained by the distortive effect of the studies measuring rGSH by Elmasry et al. [45] and Al-Azzawy et al. [47]. However, their removal did not substantially reduce the magnitude of the heterogeneity $\left(\mathrm{I}^{2}=98.0 \%, p<0.001\right)$, although a reduction in effect size was observed $(\mathrm{SMD}=-1.20,95 \% \mathrm{CI}=-2.42$ to $0.030, p=0.056)$. No publication bias was found using Begg's $(p=0.19)$ and Egger's $(p=0.95)$ tests following the removal of these studies. However, the trim-and-fill method found five potential missing studies to add on the left side of the funnel plot to ensure its symmetry (Figure 5), yielding an adjusted SMD of $-2.32 ; 95 \% \mathrm{CI}=-3.57$ to $-1.07, p<0.001$. Although publication bias analysis was not performed due to the reduced number of articles available, similar results were obtained when removing studies measuring tGSH (Figure 9). Taken together, these analyses rule out significant issues related to the meta-analysis design as a source of heterogeneity.

\section{Conclusions}

To our knowledge, this is the first meta-analysis exploring the association between blood GSH concentrations and COPD. It is important to highlight that our analysis was limited to observational studies investigating GSH concentrations in RBCs/WB, biological matrices that are less likely to be affected by analytical shortcomings. The substantial heterogeneity among the included studies can still be explained by methodological factors, e.g., sample collection and handling, as well as specific patient characteristics, rather than issues related per se to the meta-analysis design. Thus, although a random-effects model was used to calculate the pooled standardized mean difference and the number of articles identified for the meta-analysis were limited, the significant reduction in blood rGSH concentrations observed in COPD patients when compared to healthy controls represents a robust finding that supports the presence of an impaired antioxidant defense mechanism in COPD. 
Author Contributions: A.Z., A.G.F. and P.P. (Panagiotis Paliogiannis) conceived the original idea and led the study team. S.S., A.A.M., C.C., P.P. (Pietro Pirina) and E.Z. jointly conceived the original idea and led the study design. E.S. and S.M. performed the systematic review research. A.Z. and P.P. (Panagiotis Paliogiannis) performed the meta-analysis. S.S. wrote the paper. All authors reviewed the final manuscript. All authors have read and agreed to the published version of the manuscript.

Funding: This research was supported by grants from the Sardinian Fondo di Sviluppo e Coesione (FSC) 2014-2020, Patto per lo Sviluppo della Regione Sardegna, L.R.7-2017 (RASSR82005).

Conflicts of Interest: The authors declare no conflict of interest.

\section{References}

1. Bagdonas, E.; Raudoniute, J.; Bruzauskaite, I.; Aldonyte, R. Novel aspects of pathogenesis and regeneration mechanisms in COPD. Int. J. Chron. Obstruct. Pulmon. Dis. 2015, 10, 995-1013.

2. Duangrithi, D.; Saiprom, K.; SaeTew, J.; Sa-u, Y. Impact of exacerbation on the errors of inhaler techniques in COPD patients. J. Appl. Pharm. Sci. 2017, 7, 84-89.

3. Quaderi, S.A.; Hurst, J.R. The unmet global burden of COPD. Glob. Health Epidemiol. Genom. 2018, 3, e4. [CrossRef]

4. Rahman, I. The Role of Oxidative Stress in the Pathogenesis of COPD. Treat. Respir. Med. 2005, 4, 175-200. [CrossRef]

5. Rahman, I.; Adcock, I.M. Oxidative stress and redox regulation of lung inflammation in COPD. Eur. Respir. J. 2006, 28, 219-242. [CrossRef] [PubMed]

6. Forbes, L.J.L.; Kapetanakis, V.; Rudnicka, A.R.; Cook, D.G.; Bush, T.; Stedman, J.R.; Whincup, P.H.; Strachan, D.P.; Anderson, H.R. Chronic exposure to outdoor air pollution and lung function in adults. Thorax 2009, 64, 657-663. [CrossRef] [PubMed]

7. Salvi, S.S.; Barnes, P.G. Chronic obstructive pulmonary disease in non-smokers. Lancet 2009, 374, 733-743. [CrossRef]

8. U.S. Department of Health and Human Services. How Tobacco Smoke Causes Disease: The Biology and Behavioral Basis for Smoking-Attributable Disease: A Report of the Surgeon General. Department of Health and Human Services, Centers for Disease Control and Prevention, National Center for Chronic Disease Prevention and Health Promotion, Office on Smoking and Health; U.S. Government Printing Office: Washington, DC, USA; Atlanta, GA, USA, 2010.

9. Van der Toorn, M.; Rezayat, D.; Kauffman, J.F.; Bakker, S.J.L.; Gans, R.O.B.; Koëter, G.H.; Choi, A.M.K.; Van Oosterhout, A.J.M.; Slebos, D.J. Lipidsoluble components in cigarette smoke induce mitochondrial production of reactive oxygen species in lung epithelial cells. Am. J. Physiol. Lung Cell. Mol. Physiol. 2009, 297, L109-L114. [CrossRef] [PubMed]

10. Tkaczyk, J.; Vízek, M. Oxidative stress in the lung tissue-Sources of reactive oxygen species and antioxidant defence. Prague Med. Rep. 2007, 108, 105-114.

11. Dröge, W. Free radicals in the physiological control of cell function. Physiol. Rev. 2002, 82, 47-95. [CrossRef]

12. Zinellu, A.; Fois, A.G.; Sotgia, S.; Zinellu, E.; Bifulco, F.; Pintus, G.; Mangoni, A.A.; Carru, C.; Pirina, P. Plasma protein thiols: An early marker of oxidative stress in asthma and chronic obstructive pulmonary disease. Eur. J. Clin. Investig. 2007, 28, 1942-1948. [CrossRef] [PubMed]

13. Meister, A. Glutathione deficiency produced by inhibition of its synthesis, and its reversal; applications in research and therapy. Pharmacol. Ther. 1991, 51, 155-194. [CrossRef]

14. Heffner, J.A.; Repine, J.E. State of the art: Pulmonary strategies of antioxidant defense. Am. Rev. Respir. Dis. 1989, 140, 531-554. [CrossRef] [PubMed]

15. Jones, D.P. Redox potential of GSH/GSSG couple: Assay and biological significance. Methods Enzymol. 2002, 348, 93-112. [PubMed]

16. Beeh, K.M.; Beier, J.; Koppenhoefer, N.; Buhl, R. Increased glutathione disulfide and nitrosothiols in sputum supernatant of patients with stable COPD. Chest 2004, 126, 1116-1122. [CrossRef] [PubMed]

17. Lee, W.; Thomas, P.S. Oxidative Stress in COPD and Its Measurement through Exhaled Breath Condensate. Clin. Transl. Sci. 2009, 2, 150-155. [CrossRef] [PubMed]

18. Drost, E.M.; Skwarski, K.M.; Sauleda, J.; Soler, N.; Roca, J.; Agusti, A.; MacNee, W. Oxidative stress and airway inflammation in severe exacerbations of COPD. Thorax 2005, 60, 293. [CrossRef] 
19. van der Vliet, A.; O’Neill, C.A.; Cross, C.E.; Koostra, J.M.; Volz, W.G.; Halliwell, B.; Louie, S. Determination of low-molecular-mass antioxidant concentrations in human respiratory tract lining fluids. Am. J. Physiol. 1999, 276, L289-L296. [CrossRef]

20. Gould, N.S.; Min, E.; Gauthier, S.; Martin, R.J.; Day, B.J. Lung glutathione adaptive responses to cigarette smoke exposure. Respir. Res. 2011, 12,1-9. [CrossRef]

21. Cross, C.E.; Van der Vliet, A.; O’Neill, C.A.; Louie, S.; Halliwell, B. Oxidants, antioxidants, and respiratory tract lining fluids. Environ. Health Perspect. 1994, 102, 185-191.

22. Freels, J.L.; Robbins, R.A.; Campbell, S.C. Exhaled Breath Condensate the Past, Present, and Future. Clin. Pulm. Med. 2003, 10, 263-268. [CrossRef]

23. Wells, G.; Shea, B.; O'Connell, D.; Peterson, J.; Welch, V.; Losos, M.; Tugwell, P. The Newcastle-Ottawa Scale (NOS) for Assessing the Quality of Nonrandomised Studies in Meta-Analyses. 2013. Available online: http://www.ohri.ca/programs/clinical_epidemiology/oxford.asp (accessed on 11 October 2020).

24. Wan, X.; Wang, W.; Liu, J.; Tong, T. Estimating the sample mean and standard deviation from the sample size, median, range and/or interquartile range. BMC Med. Res. Methodol. 2014, 19, 135. [CrossRef] [PubMed]

25. Bowden, J.; Tierney, J.F.; Copas, A.J.; Burdett, S. Quantifying, displaying and accounting for heterogeneity in the meta-analysis of RCTs using standard and generalised Q statistics. BMC Med. Res. Methodol. 2011, 11, 41. [CrossRef] [PubMed]

26. Higgins, J.P.; Thompson, S.G. Quantifying heterogeneity in a meta-analysis. Stat. Med. 2002, 21, 1539-1558. [CrossRef] [PubMed]

27. Tobias, A. Assessing the influence of a single study in the meta-analysis estimate. Stata Tech. Bull. 1999, $47,15-17$.

28. Begg, C.B.; Mazumdar, M. Operating characteristics of a rank correlation test for publication bias. Biometrics 1994, 50, 1088-1101. [CrossRef] [PubMed]

29. Sterne, J.A.; Egger, M. Funnel plots for detecting bias in meta-analysis: Guidelines on choice of axis. J. Clin. Epidemiol. 2001, 54, 1046-1055. [CrossRef]

30. Duval, S.; Tweedie, R. Trim and fill: A simple funnel-plot-based method of testing and adjusting for publication bias in meta-analysis. Biometrics 2000, 56, 455-463. [CrossRef]

31. Liberati, A.; Altman, D.G.; Tetzlaff, J.; Mulrow, C.; Gøtzsche, P.C.; Ioannidis, J.P.; Clarke, M.; Devereaux, P.J.; Kleijnen, J.; Moher, D. The PRISMA statement for reporting systematic reviews and meta-analyses of studies that evaluate healthcare interventions: Explanation and elaboration. BMJ 2009, 339, b2700. [CrossRef]

32. Fläring, U.B.; Rooyackers, O.E.; Hebert, C.; Bratel, T.; Hammarqvist, F.; Wernerman, J. Temporal changes in whole-blood and plasma glutathione in ICU patients with multiple organ failure. Intensive Care Med. 2005, 31, 1072-1078. [CrossRef]

33. Biljak, V.R.; Rumora, L.; Cepelak, I.; Pancirov, D.; Popović-Grle, S.; Sorić, J.; Grubisić, T.Z. Glutathione cycle in stable chronic obstructive pulmonary disease. Cell Biochem. Funct. 2010, 28, 448-453. [CrossRef] [PubMed]

34. Calikoğlu, M.; Unlü, A.; Tamer, L.; Ercan, B.; Buğdayci, R.; Atik, U. The levels of serum vitamin C, malonyldialdehyde and erythrocyte reduced glutathione in chronic obstructive pulmonary disease and in healthy smokers. Clin. Chem. Lab. Med. 2002, 40, 1028-1031. [CrossRef] [PubMed]

35. Agacdiken, A.; Basyigit, I.; Ozden, M.; Yildiz, F.; Ural, D.; Maral, H.; Boyaci, H.; Ilgazli, A.; Komsuoglu, B. The effects of antioxidants on exercise-induced lipid peroxidation in patients with COPD. Respirology 2004, 9, 38-42. [CrossRef] [PubMed]

36. Faucher, M.; Steinberg, J.G.; Barbier, D.; Hug, F.; Jammes, Y. Influence of chronic hypoxemia on peripheral muscle function and oxidative stress in humans. Clin. Physiol. Funct. Imaging 2004, 24, 75-84. [CrossRef] [PubMed]

37. Foschino Barbaro, M.P.; Serviddio, G.; Resta, O.; Rollo, T.; Tamborra, R.; Carpagnano, E.G.; Vendemiale, G.; Altomare, E. Oxygen therapy at low flow causes oxidative stress in chronic obstructive pulmonary disease: Prevention by N-acetyl cysteine. Free Radic. Res. 2005, 39, 1111-1118. [CrossRef] [PubMed]

38. Nadeem, A.; Raj, H.G.; Chhabra, S.K. Increased oxidative stress and altered levels of antioxidants in chronic obstructive pulmonary disease. Inflammation 2005, 29, 23-32. [CrossRef]

39. Parija, M.; Bobby, Z.; Kumar, V.; Saradha, B. Oxidative stress and protein glycation in patients with chronic obstructive pulmonary disease. Indian J. Physiol. Pharmacol. 2005, 49, 95-98.

40. Rai, R.R.; Phadke, M.S. Plasma oxidant-antioxidant status in different respiratory disorders. Indian J. Clin. Biochem. 2006, 21, 161-164. [CrossRef] 
41. Jammes, Y.; Steinberg, J.G.; Ba, A.; Delliaux, S.; Brégeon, F. Enhanced exercise-induced plasma cytokine response and oxidative stress in COPD patients depend on blood oxygenation. Clin. Physiol. Funct. Imaging 2008, 28, 182-188. [CrossRef]

42. Mercken, E.M.; Gosker, H.R.; Rutten, E.P.; Wouters, E.F.; Bast, A.; Hageman, G.J.; Schols, A.M. Systemic and pulmonary oxidative stress after single-leg exercise in COPD. Chest 2009, 136, 1291-1300. [CrossRef]

43. Ahmad, A.; Shameem, M.; Husain, Q. Altered oxidant-antioxidant levels in the disease prognosis of chronic obstructive pulmonary disease. Int. J. Tuberc. Lung Dis. 2013, 17, 1104-1109. [CrossRef] [PubMed]

44. Arja, C.; Surapaneni, K.M.; Raya, P.; Adimoolam, C.; Balisetty, B.; Kanala, K.R. Oxidative stress and antioxidant enzyme activity in South Indian male smokers with chronic obstructive pulmonary disease. Respirology 2013, 18, 1069-1075. [PubMed]

45. Elmasry, S.A.; Al-Azzawi, M.A.; Ghoneim, A.H.; Nasr, M.Y.; AboZaid, M.M.N. Role of oxidant-antioxidant imbalance in the pathogenesis of chronic obstructive pulmonary disease. Egypt. J. Chest Dis Tuberc. 2015, 64, 813-820. [CrossRef]

46. Kodama, Y.; Kishimoto, Y.; Muramatsu, Y.; Tatebe, J.; Yamamoto, Y.; Hirota, N.; Itoigawa, Y.; Atsuta, R.; Koike, K.; Sato, T.; et al. Antioxidant nutrients in plasma of Japanese patients with chronic obstructive pulmonary disease, asthma-COPD overlap syndrome and bronchial asthma. Clin. Respir. J. 2017, 11, 915-924. [CrossRef] [PubMed]

47. Al-Azzawi, M.A.; Ghoneim, A.H.; Elmadbouh, I. Evaluation of Vitamin D, Vitamin D Binding Protein Gene Polymorphism with Oxidant-Antioxidant Profiles in Chronic Obstructive Pulmonary Disease. J. Med. Biochem. 2017, 28, 331-340. [CrossRef] [PubMed]

48. Jha, S.; Bhattacharjee, D.; Chowdhuri, S.; Mitra, A.; Das, A.; Mukherjee, K. Oxidants and Antioxidants in COPD Associated with Tobacco Smoke and Biomass Exposure. J. Evol. Med. Dent. Sci. 2019, 8, 3449-3453. [CrossRef]

49. Saribal, D.; Hocaoglu-Emre, F.S.; Aydemir, B.; Akyolcu, M. Determination of Relationship between Lipid Peroxidation, Antioxidant Defence, Trace Elements and Hemorheology in COPD. Trace Elem. Electroly. 2019, 36, 131-136. [CrossRef]

50. van 't Erve, T.J.; Wagner, B.A.; Ryckman, K.K.; Raife, T.J.; Buettne, G.R. The Concentration of Glutathione in Human Erythrocytes is a Heritable Trait. Free Radic. Biol. Med. 2013, 65, 742-749. [CrossRef]

51. Carru, C.; Zinellu, A.; Pes, G.M.; Marongiu, G.; Tadolini, B.; Deiana, L. Ultrarapid capillary electrophoresis method for the determination of reduced and oxidized glutathione in red blood cells. Electrophoresis 2002, 23, 1716-1721. [CrossRef]

52. Carru, C.; Zinellu, A.; Sotgia, S.; Marongiu, G.; Farina, M.G.; Usai, M.F.; Pes, G.M.; Tadolini, B.; Deiana, L. Optimization of the principal parameters for the ultrarapid electrophoretic separation of reduced and oxidized glutathione by capillary electrophoresis. J. Chromatogr. A 2003, 1017, 233-238. [CrossRef]

53. Zinellu, A.; Sotgia, S.; Usai, M.F.; Zinellu, E.; Deiana, L.; Carru, C. GSH depletion after erythrocytes acidic treatment is related to intracellular hemoglobin levels. Clin. Chim. Acta. 2006, 366, 363. [CrossRef] [PubMed]

54. Beutler, E.; Duron, O.; Kelly, B.M. Improved method for the determination of blood glutathione. J. Lab. Clin. Med. 1963, 61, 882-888. [PubMed]

55. Jones, D.P.; Carlson, J.L.; Samiec, P.S.; Sternberg, P.; Mody, V.C.; Reed, R.L.; Brown, L.A. Glutathione measurement in human plasma. Evaluation of sample collection, storage and derivatization conditions for analysis of dansyl derivatives by HPLC. Clin. Chim. Acta. 1998, 275, 175-184. [CrossRef]

56. Zinellu, A.; Zinellu, E.; Sotgiu, E.; Fois, A.G.; Paliogiannis, P.; Scano, V.; Piras, B.; Sotgia, S.; Mangoni, A.A.; Carru, C.; et al. Systemic transsulfuration pathway thiol concentrations in chronic obstructive pulmonary disease patients. Eur. J. Clin. Investig. 2020, 7, e13267.

57. Paliogiannis, P.; Fois, A.G.; Sotgia, S.; Mangoni, A.A.; Zinellu, E.; Pirina, P.; Carru, C.; Zinellu, A. Circulating malondialdehyde concentrations in patients with stable chronic obstructive pulmonary disease: A systematic review and meta-analysis. Biomark. Med. 2018, 12, 771-781. [CrossRef]

Publisher's Note: MDPI stays neutral with regard to jurisdictional claims in published maps and institutional affiliations. 